\title{
PENGARUH TERAPI MUROTTAL AL-QUR'AN TERHADAP STRES PADA LANSIA
}

\author{
Ina Nisrina Bahrir1, Siti Komariah2 \\ 1 Universitas Nurul Jadid, Probolinggo \\ ${ }^{2}$ Dinas kesehatan Pasuruan
}

\section{ABSTRACT}

Stress is the external events and situations that burden the environment adaptability, individuals, particularly in the form of emotional and psychological burden, prolonged stress can be bad for the health of the elderly. Environment can support or interfere with the function of the physical and social circumstances occur due to lack of family role, then the role of the social environment that could cause conflicts and shocks tabe streess. Murottal Qur'an that contains some verses of the Qur'an to clear the heart and cleanse the soul elderly, especially for the elderly who are experiencing stress. This research quantitative research methods approach pre asExperiment with one group pretest - Posttest. The amount of the total sample of 40 respondents. This research subject is old egg who wexperience stress in UPT. Social services elderly Bondowoso. The sample used purposive sampling. Measurement data using stress questionnaire, observation before and after Murottal Qur'an. analysis using the Wilcoxon Signed Rank Test. The results showed before doing therapy murottal Qur'an many people. hare experience severe stress as muchas (26 seniors), moderate stress (14 seniors), and mild stress (0), after doing therapy murottal Qur'an stress on elderly, it decreate to be moderate stress 140 old egs), stress (weight O), and mild stress (O). In hypothesis testing using the Wilcoxon Signed Rank Test results were obtained sig. $p$ value $=0.000$, which means $p$ value $<0.05$ So HI accepted. The conclusion from this study resereh, the Qur'an murottal therapy candecrease elderty stress

Keywords: Knowledge, Murottal Qur'an, Stress At Elderly. 


\section{ABSTRAK}

Stres adalah kejadian ekternal serta situasi lingkungan yang membebani kemampuan adaptasi, individu, terutama berupa beban emosional dan kejiwaan, stres yang berkepanjangan dapat berdampak buruk bagi kesehatan lansia. Lingkungan dapat mendukung atau mengganggu fungsi fisik dan sosial keadaan tersebut terjadi karena kurangnya peran keluarga dan peran dari lingkungan sosial yang dapat menimbulkan konflik dan guncangan dalam diri lansian yang mengalani stres. Murottal Al-Qur'an yang di dalamnya berisi ayat - ayat suci Al-Qur'an baik untuk menjernihkan hati membersihkan jiwa Bagi lansia, Terutama bagi lansia yang mengalami stress. Metode penelitian ini merupakan penelitian kuantitatif dengan metode pra Eksperimen dengan pendekatan One Group Pretest - Postest. Jumlah sampel keseluruhan 40 responden. Subjek penelitian ini terhadap lansian yang mengalami stres di UPT. Pelayanan sosial lanjut usia bondowoso. Sampel yang di gunakan adalah purposive sampling. Pengukuran data dengan menggunakan kuesioner stres, observasi sebelum dan sesudah diberikan Murottal Al-Qur'an. analisis menggunakan uji Wilcoxon Signed Rank Test. Hasil penelitian menunjukan sebelum di lakukan terapi murottal al-Qur'an banyak yang mengalami stres berat sebanyak (26 lansia), stres sedang (14 lansia), dan stres ringan (0), setelah di lakukan terapi murottal al-Qur'an stres pada lansia menurunan stres sedang (40 lansian), stres (berat 0), dan stres ringan (0). Pada uji hipotesa menggunakan Wilcoxon Signed Rank Test diperoleh hasil yang sig. $\mathrm{p}$ value $=0,000$ yang artinya $\mathrm{p}$ value $<0,05$ Maka HI diterima. Kesimpulan dari penelitian ini adalah bahwa terapi murottal Al-Qur'an dapat meneurunkan stres pada lansia

Kata Kunci : Pengetahuan, Murottal Al-Qur'an ,Stres Pada Lansia. 


\section{PENDAHULUAN}

Membaca Al-Qur'an dan mendengarkan bacaan Al-Qur'an merupakan ibadah dan mendapat pahala, serta meringankan beban dengan catatan mendengarkan dengan baik dan tenang, sebagaima di jelaskan dalam surat (7) Al A'raaf ayat 204 yang telah disebutkan di bawah ini:

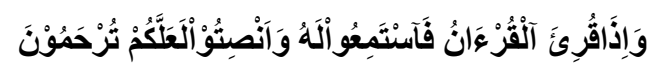

Artinya: "Dan apabila di bacakan AlQur'an maka dengarkanlah (baik-baik) dan perhahtikanlah dengan tenang agar kamu mendapat rahmat"

Dari Al-Qur-an yang telah diterangkan di atas bahwasanya mendengarkan Al-Qur'an dengan baik dan tenang bisa meringankan beban dan mendapat pahala.

Mendengarkan bacaan AlQur'an dengan baik dapat menghibur saat perasaan sedih, menenangkan jiwa yang gelisah dan melunakkan hati yang keras, serta mendatangkan petunjuk. Itulah yang di maksudkan dengan rahmat Allah yang diberikan kepada orang yang mendengarkan bacaan al Qur'an dengan baik. Demikian besar mukjisat Al-Qur'an sebagai wahyu ilahi, yang tidak bosan bosan orang membaca dan mendengarkannya. Semakin sering orang membaca dan mendengarkannya semakin terpikat hatinya kepada Al-Qur'an itu; bila Al-Qur'an itu di baca dengan lidah yang fasih, dengan suara yang baik dan merdu akan lebih memberi pengaruh ke pada jiwa orang yang mendengarkannya sehinga seolah olah yang medengarnya sudah ada di alam gaib, bertemu langsung dengan khalilnya.

Lansia sering mengalami stres karena mereka harus berhadapan dengan kehilangan peran diri, kependudukan sosial, serta perpisahan dengan orang orang yang dicintai. Sekitar $70 \%$ lanjut usia (lansia) di Jawa Timur diduga stres . Pada Lansia tidak hanya terjadi stres psikologis tetapi juga dapat terjadi stres fisik. Oleh sebab itu, perlu suatu penanganan untuk mengurangi stres pada lansia.

Berdasarkan sensus penduduk tahun 1971, jumlah penduduk berusia 60 tahun ke atas sebesar 5,3 juta $(4,5 \%)$ dari jumlah penduduk. Selanjutnya, pada tahun 1980, jumlah ini meningkat menjadi \pm 8 juta $(5,5 \%)$ dari jumlah penduduk dan pada tahun 1990, jumlah ini meningkat menjadi $\pm 11,3$ juta (6,4\%). Pada tahun 2000, diperkirakan meningkat sekitar 15,3 juta $(7,4 \%)$ dari jumlah penduduk, dan pada tahun 2005, jumlah ini diperkirakan meningkat menjadi $\pm 18,3$ juta $(8,5 \%)$.

Jumlah lansia di Indonesia memiliki presentase sebanyak $7,6 \%$ dari jumlah penduduk di Indonesia, terdapat 7 Propinsi di Indonesia yang memilki jumlah lansia terbanyak. Propinsi Jawa Timur pada tahun 2008 merupakan propinsi dengan peringkat kedua di Indonesia dengan jumlah lansia terbanyak yaitu 3,2 juta jiwa setelah Propinsi Yogyakarta.

Berdasarkan dari hasil studi pendahuluan pada bulan Juni 2015 yang dilakukan oleh peneliti dari Drs. Agung Pambudi, M.Si yang menjadi Kepala Ruangan UPT (Unit Pelaksana Teknis), bahwa terdapat 40 lansia yang mengatakan alasan lansia tinggal di UPT (Unit Pelaksana Teknis) Pelayanan Sosial Lanjut Usia Bondowoso, setelah peneliti selesai melakukan studi 
$\begin{array}{llr}\text { pendahuluan } & \text { dengan } & \text { Kepala } \\ \text { Ruangan UPT (Unit } & \text { Pelaksana } \\ \text { Teknis), peneliti } & \text { langsung }\end{array}$ melakukan studi pendahuluan pada lansia, alasan mereka tinggal di UPT (Unit Pelaksana Teknis) karena rumah (tempat tinggal), dan lingkungan merupakan hal yang sangat penting bagi lansia. Banyak sekali lansia yang harus pindah ketempat tinggal yang baru misalnya saat ada di tempat Panti Werda di sana tidak menutup kemungkinan lansia merasa stres, dikarenankan harus melakukan adaptasi terhadap lingkungan yang baru, merasa kehilangan harus berpisah dengan keluarga, tidak bisa mengendalikan emosionalnya sendiri, tidak bisa menyesuaikan diri terhadap lingkungan, hal ini secara fisik, akan menggangu psikososialnya dan kepuasan terhadap lingkungan yang berbeda misalnya ketika lansia masih tinggal bersama keluarga secara fisik, psikologis dan kepuasan terhadap lingkungan akan mempunyai perasan yang positif. Dari hal tersebut dapat menurunkan kondisi fisik dan mentalnya sehingga dapat mengakibatkan stres pada lansia.

Berdasarkan latar belakang di atas, maka penulis tertarik untuk mengadakan penelitian tentang "Pengaruh Terapi Murottal Al-Qu'an Terhadap Stres Pada Lansia di UPT Pelayanan Sosial Lanjut Usia Bondowoso". 


\section{METODE PENELITIAN}

Design Penelitian. Desain penelitian yang digunakan adalah Pra Eksperimen dengan pendekatan One Group Pretes Postest. Pada penelitian ini populasi yang ada adalah sebanyak 90 lansia di UPT Pelayanan Sosial Lanjut Usia Bondowoso. Teknik penentuan sampel yang dilakukan dalam penelitian ini yaitu purposive sampling teknik pengambilan sampel dilakukan secara purposive sampling yaitu suatu tekhnik pengambilan sampel secara sengaja. Kriteria inklusi adalah Lansia yang bertempat di UPT Sosial Lanjut Usia Bondowoso, Lansia yang berumur 60 sampai 90 tahun, Lansia yang Bersedia menjadi responden dalam penelitian.

Kriteria ekslusi dalam penelitian ini adalah Lansia dengan kesadaran yang kurang baik, Lansia yang lebih dari 90 tahun, Lansia yang tidak mau dijadikan responden.

Prosedur Penelitian. Peneliti mengajukan permohonan penelitian dan meminta responden untuk mengisi kuesioner, setelah mendapatkan persetujuan dari responden, pengumpulan data dimulai.

Analisis Data. Tekhnik Statistik yang menjadi pilihan dari penelitian ini menggunakan Statistik non parametrik (Wilcoxon) statistik nonparametrik adalah yang berhubungan dengan data yang berbentuk ranking atau data kuantitatif (skala nominal atau ordinal) data kuantitatif yang tidak berdistribusi normal.

\section{HASIL PENELITIAN}

Tabel 1 Distribusi frekuensi stres Responden Sebelum Mendapatkan perlakuan

\begin{tabular}{lcc}
\hline Tingkat Stres & Frekuensi & Persentase \\
\hline Stres Ringan & 0 & $0 \%$ \\
Stres Sedang & 14 & $35 \%$ \\
Stres Berat & 26 & $65 \%$ \\
Total & $\mathbf{4 0}$ & $\mathbf{1 0 0 \%}$ \\
\hline
\end{tabular}

Sumber: Data primer

Dari table 1 di atas di dapatkan lansia yaitu dari responden yang mengalami stress ringan tidak ada (0), stres sedang berjumlah14 (35\%), dan Stres berat berjumlah 26 (65\%).

Tabel 2 Distribusi Frekuensi stres Responden Mendapat Perlakuan.

\begin{tabular}{lcc}
\hline \multicolumn{1}{r}{ Sesudah } & Frekuensi & Persentase \\
\hline Stres Ringan & 0 & $0 \%$ \\
StresSedang & 40 & $100 \%$ \\
StresBerat & 0 & $0 \%$ \\
Total & $\mathbf{4 0}$ & $\mathbf{1 0 0 \%}$ \\
\hline
\end{tabular}

Sumber: Data primer

Berdasarkan data table 2 di atas, di dapatkan lansia yaitu 40 Lansia yang mengalami stress sesudah mendapat perlakuan Murottal Al-Qur'an pada lansia yang mengalami stres di UPT.Pelayanan Sosial Lanjut Usia Bondowoso, yaitu responden yang mengalami stress Ringan tidak ada, responden yang mengalami stress Sedang sebanyak 40 lanjut usia (100\%), respondenyang mengalami stress berat tidak ada.

Sumber: Data primer

Berdasarkan data table 2 di atas, di dapatkan lansia yaitu 40 Lansia yang mengalami stress sesudah mendapat perlakuan Murottal Al-Qur'an pada lansia yang mengalami stres di UPT.Pelayanan Sosial Lanjut Usia Bondowoso, yaitu responden yang mengalami stress Ringan tidak ada, responden yang mengalami stress sedang sebanyak 40 lanjut usia 
(100\%), respondenyang mengalami

stress berat tidak ada.

Tabel 3 AnalisisDistribusi stres pada lansia sebelum dan sesudah di lakukan terapi murotta Al-Qur'an.

\begin{tabular}{lcccc}
\hline Murottal Al- Qur'an & \multicolumn{2}{c}{ Pre test } & \multicolumn{2}{c}{ Post test } \\
\cline { 2 - 4 } Stres pada lansia & Frekwensi & Persentase & Frekwensi & Persentase \\
& $(\mathrm{n})$ & $(\%)$ & $(\mathrm{n})$ & $(\%)$ \\
Stres Ringan & 0 & $0 \%$ & 0 & $0 \%$ \\
Stres Sedang & 14 & $35 \%$ & 40 & $40 \%$ \\
Stres Berat & 26 & $65 \%$ & 0 & $0 \%$ \\
Total & 40 & $100 \%$ & 40 & $100 \%$ \\
& $\mathbf{N}=\mathbf{4 0} \mathbf{P}$ Value $=\mathbf{0 , 0 0 0}$ yang berarti $<\mathbf{0 , 0 5}$ & \\
\hline
\end{tabular}

Berdasarkan table 3 hasil uji statistik Wilcoxon Sign Rank Test, menunjukkan nilai signifikasi $(\mathrm{P}$ value $=0,000)$ dimana hal ini berarti $\mathrm{P}$ value $<0,05$ sehingga $\mathrm{H} 1$ diterima artinya ada pengaruh stres pada lansia sebelum dan sesudah pemberian terapi murottal AlQur'an.

\section{PEMBAHASAN}

Berdasarkan Tabel 3 analisis dapat dilihat bahwa stres yang di alami pada lansia sesudah di lakukan terapi murottal Al-Qur'an dalam hasil penelitian yang mengalamistresringan tidak ada , yang mengalamistres sedangberjumlah40 Lanjut usia(100\%) danresponden yang mengalami Stres berat tidak ada. Artinya stres yang dirasakan oleh responden berada dalam katagori sedang dari sesudah di lakukan terapi murottal Al-Qur'an.

Dari hasil di atas reponden mendengarkan lantunan ayat suci Al-Qur'an terlebih dahulu dan sesudah di dengarkan kita lakukan pengukuran stres dengan menggunakan kuesioner sebanyak 40 pertanyaan pada responden laki - laki maupun perepuan dan di sana umurnya dari 60 sampai 90 berjumlah sebanyak 40 responden yang kita lakukan terapi murottal
Al-Qur'an di tempat UPT.Pelayanan Sosial Lanjut Usia Bondowoso, berdasarkan hasil dari sesudah di lakukan terapi murottal Al-Qur'an pada responden dalam hasilnya stres menurun dari stres sedang dan stres berat menjadi stres sedang dari hasil itu sudah bisa di ketahui bahwa terapi murottal AlQur'an terdapat pengaruh pada responden yg mengalami stres.

Ada Pengaruh Terapi Murottal Al-Qur'an Terhadap Stres Pada Lansian setelah dilakukan tabulasi silang kemudian dilakukan perhitungan dengan menggunakan uji SPSS dengan wilcoxon dan diperoleh hasil signifikan 0,000 dan lebih kecil dari pada P. 0,05, maka didapatkan kesimpulan $\mathrm{HI}$.

Dari penelitian terapi murottal al-Qur'an sebelum di lakukan mendengarkan lantunan ayat suci al-Qur'an dan Sesudah di lakukan di lakukan mendengarkan lantunan aya suci al-Qur'an dari keduanya ada perbedaan yang mana sebelum di lakukan terapi murottal al-Qur'an dalam hasil responden mengalami stres sedang dan stres berat saat setelah di lakukan terapi murottal al-Qur'an responden hasilnya menurun dalam stresnya hasilnya stres sedang yang mana terdapat Pengaruh Terapi Murottal Al-Qur'an Terhadap Stres Pada Lansian setelah dilakukan 
tabulasi silang kemudian dilakukan perhitungan dengan menggunakan uji SPSS dengan wilcoxon dan diperoleh hasil signifikan 0,000 dan lebih kecil dari pada P. 0,05, maka didapatkan kesimpulan $\mathrm{Ha}$.

Menurut bahwa stimulasi AlQur'an di dominasi oleh gelombang delta yang muncul di daerah frontal dan sentral baik sebelah kanan maupun kiri otak. Fungsi daerah frontal yaitu sebagai fungsi intelektual umum dan pengontrol emosi, sedangkan fungsi dari daerah sentral sebagai pusat pengontrol gerakan - gerakan yang dilakukan. Sehingga stimulasi AlQur'an dapat memberikan ketenangan, ketentraman dan kenyamanan.

Al-Qur'an merupakan obat yang mujarab. Baik penyakit hati maupun penyakit fisik, baik penyakit dunia ataupun penyakit akhirat. Berikut ini adalah beberapa manfaat dari murottal (mendengarkan bacaan ayat-ayat Al-Qur'an) antara lain:

Mendengarkan bacaan ayatayat Al-Qur'an dengan tartil akan mendapatkan ketenangan jiwa.

Lantunan Al-Qur'an secara

fisik mengandung unsur suara manusia, suara manusia atau seseorang adalah instrumen atau alat penyembuhan yang sangat menakjubkan dan alat yang mudah dijangkau. Suara dapat menurunkan hormonhormon stres, mengaktifkan hormon endoprin alami, meningkatkan perasaan rileks, dan mengalihkan perhatian dari rasa takut, tegang, memperbaiki sistem kimia tubuh sehingga menurunkan tekanan darah serta memperlambat pernafasan, detak jantung, denyut nadi, dan aktifitas gelombang otak.

\section{KESIMPULAN}

Dari data yang diperoleh, peneliti memperoleh kesimpulan yakni:

1. Sebelum Tingkat stres pada lansia sebelum dilakukan terapi murottal al-Qur'an yang berada di UPT. Pealayanan sosial lanjut usia bondowoso termasuk katagori stres sedang dan stres berat.

2. Stres pada lansia sesudah di lakukan terapi murottal alQur'an yang berada di UPT. Pelayanan sosial lanjut usia bondowoso termasuk kategori stres ringan.

3. Ada pengaruh terapi murottal al-Qur'an terhadap stres pada lansia di UPT. Pelayanan Sosial Lanjut Usia Bondowoso.

\section{SARAN}

1. Bagi Praktik Keperawatan

Hasil penelitian ini, dapat digunakan sebagai masukan dan tambahan ilmu bagi seluruh profesi keperawatan dan dapat memberikan informasi tentang masalah kesehatan khususnya pentingnyaTerapi Murottal AlQur'an.

2. Bagi Institusi

Diharapkan selalu memberikan masukan terhadap mahasiswa dan mahasiswi dalam membuat skripsi Pengaruh Terapi Murottal Al-Qur'an Terhadap Tingkat emosional lebih sempurna.

3. Bagi Profesi

Sebagai tenaga kesehatan dapat memberikan penyuluhan terhadap santri khususnya halhal yang berkaitan dengan pemicu timbulnya stress dan cara menangani stres.

4. Bagi Responden

Sebaiknya lansia dapat mengatur stress dengan 
menghindari berdiam diri .Serta memperhatikan kondisi psikologis dan kesehatan lansia.

\section{DAFTAR PUSTAKA}

1. Al-Qur'anul Surat Al-A'raf ayat : 204

2. Al Khoif Billah Moh. 2015. Pengaruh Pemberian Terapi Pemberian Al-Qur'an terhadap Waktu Pulih Sadar Pasien Kannker Payudara dengan Ansietas General. Naskah Publikasi.

3. Aji Permana Chandra. 2013. Hubungan antara Tingkat Stres Lansia dan Kejadian Hipertensi pada Lansia. Skripsi. Jember: Universitas Negeri Jember.

4. Aizid Rizem. 2015. Melawan Stres dan Depresi. Yogyakarta: Saufa.

5. Aryana Oka Kade, Pengaruh Tehnik Relaksasi Benson Terhadap Penurunan Tingkat Stres Lansia Di UNIT Rehabilitas Sosial, Wening Wardoyo Ungaran, 2015

6. Ericha Aditya Raharja. 2013. Hubungan antara Tingkat Depresi dengan Kejadian Insomnia pada Lanjut Usia. Skripsi. Jember: Universitas Negri Jember.

7. Had aufana Nuar. 2012. Perbedaan efektifitas Terapi Musik Klasik dan Terapi Musik Murottal terhadap Perkembangan Kognitif anak Autis. Skripsi. Surakarta. STIKes Aisyiyah.

8. Haeroni. 2012. Pengaruh Membaca Al-Qur'an (Suroh ArRohman) terhadap Demensia pada Lansia. Skripsi. STIKes Ngudi Waluyo Ungaran.

9. Huddinfati. 2015. Sejarah Ringkas Al-Qur'an. Yoyakarta: Kiswatun Publishing.
10.Nugroho Wahyu. H. 2012. Keperawatan Gerontik Dan Geriatrik. Jakarta. Buku Kedokteran EGC.

11.Irawati Yeni. 2013. Pengaruh Murottal Al-Qur'an terhadap Penurunan Tingkat Kecemasan Pasien Diabetes Melitus.Skripsi. Probolinggo. STIKes Nurul Jadid.

12.Irfandi. 2014. Efektifitas Relaksasi Religius (Dzikir) terhadap Penurunan Depresi di ?UPT Pelayanan Sosial Lansia Bondowoso. Skripsi. Probolinggo: STIKes Nurul Jadid.

13.Lestari Titik. 2015. Kumpulan Teori untuk Kajian Pustaka Penelitian Kesehatan. Yogyakarta: Jon Buid.

14.Lestari Maya. 2015. Hubungan Penerapan Panishment (Hukuman) dengan Tingkat Sters Santri Wati Wilayah AzZainiyah. Probolinggo: STIKes Nurul Jadid.

15.Jihad, Ahmad, 2011, Efektifitas Hukuman Terhadap Kedisiplinan Santri Di Pondok Pesantren Daar El-qolam, Skripsi, Fakultas Ilmu Tarbiyah Dan Keguruan Universitas Islam Negeri Syarif Hidayatullah, Jakarta

16. Mardiana Yanih. 2014. Hubungan antara Tingkat Stres Lansia dan Kejadian Hipertensi pada Lansia. Jakarta Jurnal.

17. Mashudin farid 2012, Psikologi Konseling, Bangutapan Jogjakarta, Dirusdi Toanto, 192

18. Novianti. dkk. 2012. Efektifitas Mendengarkan Bacaan AlQur'an terhadap Skor Kecemasan pada Lansia. Jurnal Kebidanan dan Keperawatan. Vol. 8. No. 1. Juni. 2012.

19.Putri Rahma dwi. 2010. Perbedaan Tingkat Stres Pada Lansia yang bertempat tinggal 
dirumah dan UPT. Skripsi. Universitas Jember.

20.Pandila. 2013. Buku Ajar Keperawatan Gerontik. Haiki. Yogyakarta

21.Putra Rizema Sitiatava. 2012. Panduan Riset Keperawatan Dan Penulisan Ilmiah. Jogjakarta

22. Rizky Erwanto. 2011. Pengaruh Stimulasi Humor Terhadap Penurunan Tingkat stres Pada Lansia.

23. Syamsul Arifin Abdullah. 2011. Studi Al-Qur'an. Jember. Buku Pena Salsabila.
24. Seto Sagung Rasmun. 2009. Stres Koping dan Adaptasi. Jakarta.

25.Wardani Rossyam alke. 2015. Pengaruh Terapi Musik Klasik Dan Terapi Musik Murottal Terhadap Perkembangan Kognitif Anak Autis. Aisyiyah Surakarta 